\title{
Looking back, moving forward: Promoting gender equity to fight HIV, Horizons studies 1999 to 2007
}

\author{
Julie Pulerwitz \\ Population Council \\ Annie P. Michaelis \\ Ellen Weiss \\ Population Council
}

Follow this and additional works at: https://knowledgecommons.popcouncil.org/departments_sbsr-hiv

Part of the Demography, Population, and Ecology Commons, Family, Life Course, and Society Commons, International Public Health Commons, and the Medicine and Health Commons How does access to this work benefit you? Let us know!

\section{Recommended Citation}

Pulerwitz, Julie, Annie P. Michaelis, and Ellen Weiss. 2010. "Looking back, moving forward: Promoting gender equity to fight HIV, Horizons studies 1999 to 2007," Horizons Synthesis Background Papers. Washington, DC: Population Council. Version of record: https://doi.org/10.1177/003335491012500219 


\section{LOOKING BACK, MOVING ForWARd}

\section{Promoting Gender Equity TO FIGHT HIV}

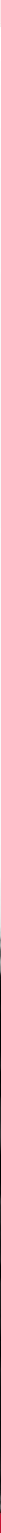

HORIZONS StUdIES 1999 TO 2007 


\section{Hgrizons}

In 1997, the Population Council initiated the Horizons Program—a decade-long USAID-funded collaboration with the Family Health International, the International HIV/AIDS Alliance, Johns Hopkins University, International Center for Research on Women, PATH, Tulane University, and the University of Alabama at Birmingham-designing, implementing, evaluating, and expanding innovative strategies for HIV prevention and care.

Horizons developed and tested ways to optimize HIV prevention, care, and treatment programs; worked to reduce stigma and improve gender-biased behaviors; and greatly expanded knowledge about the best ways to support, protect, and treat children affected by HIV and AIDS. In all its projects, Horizons strengthened the capacity of local institutions by providing support and training to colleagues.

This series of synthesis papers presents lessons learned and best practices on six key topics that Horizons investigated: HIV-related stigma, access to antiretroviral therapy, men who have sex with men, orphans and vulnerable children, HIV and gender, and prevention of mother-to-child transmission of HIV. 


\section{Promoting Gender EOUITY TO FIGHT HIV}

Gender-based inequities can hinder women's and men's ability to protect themselves from HIV infection. Horizons worked to better understand gender inequities and their consequences, developing tools to measure gender-based power dynamics and designing and testing programs to reduce gender-based biases. Horizons research focused on examining the relationships between gender norms and men's behaviors, and the effects of interventions. Our research showed that it is possible to reduce gender-based biases and HIV risk when programs engage men in thinking critically about gender inequality; focus interventions on younger men; include interactive, small-group sessions and community-based activities; use the media to promote gender equity and HIV prevention; and reach men when their partners are pregnant.

\section{Introduction}

Men have a significant influence on women's health, including women's ability to protect themselves from HIV infection [1-3]. Similarly, men's attitudes about male sexuality can lead them to engage in risky behaviors. Adolescence is a time when gender role differentials widen [4], as boys begin to enjoy privileges and freedoms reserved for men. While males often have greater mobility and opportunities compared to their female peers, these advantages also create vulnerabilities for men. For example, young men may face peer pressure to engage in unprotected sexual relationships as proof of their manliness and sexual prowess [5].

Interventions that reach young men during adolescence and early adulthood have the potential to provide a needed counterbalance to such pressures. Men and women benefit when programs and policies address their sexual and reproductive health needs and encourage more equitable sexual decision-making $[6,7]$.

When the Horizons Program began in 1997 , there were some efforts, primarily from nongovernmental organizations, to foster more gender-equitable relationships between men and women, and reach men with HIV-related information and services. As these efforts multiplied, the need to better understand the feasibility, acceptability, and impact of programming targeted to men also grew.

To address this need, Horizons and partners in Latin America, Asia, and Africa developed and implemented several intervention studies. This paper summarizes the major contributions of the Horizons' portfolio of research on gender and HIV prevention toward understanding the relationships between gender norms and men's behaviors, and the effects of interventions. 


\section{Why Gender Matters}

Early in life, both boys and girls internalize societal messages about how males and females are supposed to behave. Often these behavioral norms promote unequal gender roles and responsibilities. This can encourage behaviors that place men and their sexual partners at risk of various negative health outcomes, including HIV and other sexually transmitted infections [7-9]. Examples of such norms for men include initiating sexual activity early in life, having multiple sexual partners, and representing themselves as knowledgeable about sexual matters and disease prevention even when they are not $[8,10,11]$.

Gender norms that put men in a position of sexual dominance also limit women's ability to control their

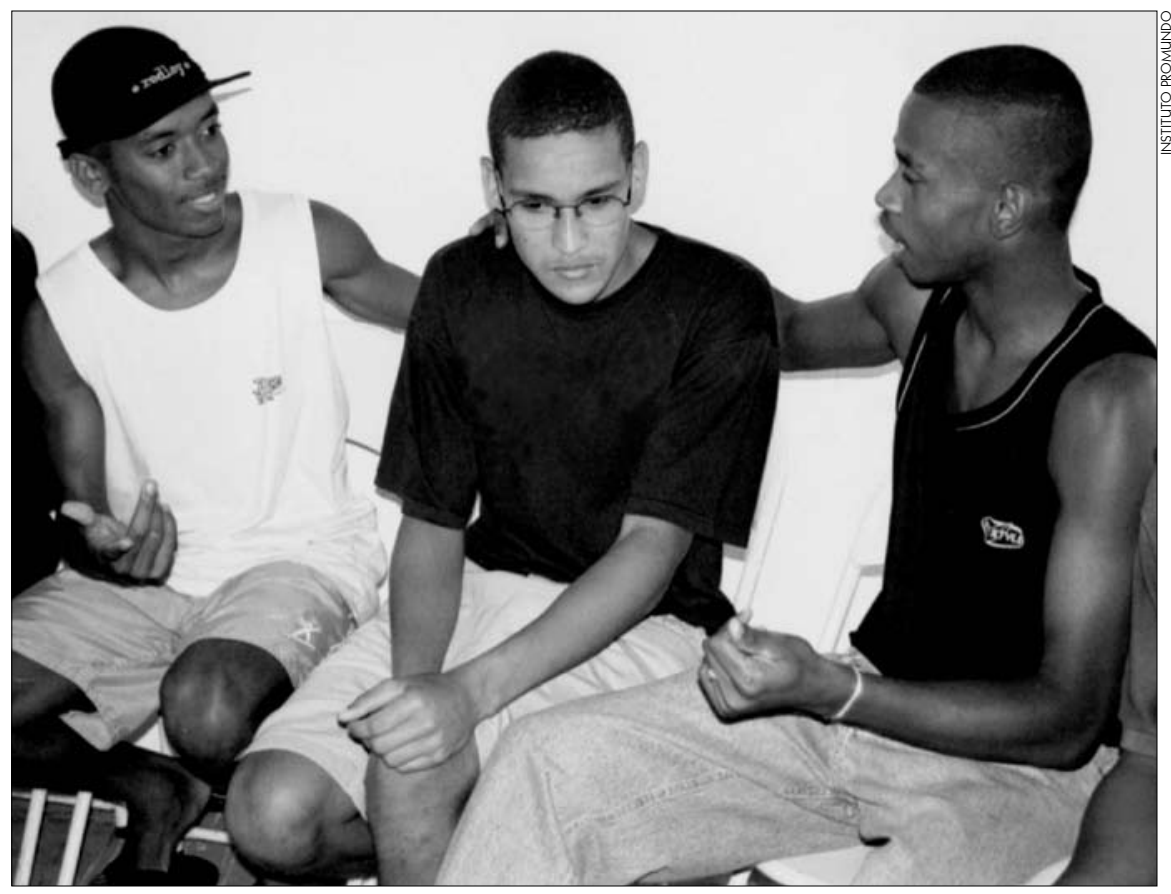

Horizons' studies in Brazil revealed a minority of more "gender equitable" men. These men sought relationships built on intimacy and equality, assumed some responsibility for reproductive health issues, and did not behave violently in intimate relationships. own reproductive and sexual health. One example is the belief that it is the man's responsibility to acquire condoms, since a young woman carrying condoms might be seen as promiscuous [12]. Another is that males must be seen to know more about sex than females, who must project an aura of innocence [13]. Gender-based power dynamics exacerbate these differences and frequently result in women having less power than men in sexual relationships. Consequently, women often cannot negotiate condom use, and have less say over the conditions and timing of sexfactors that put them at greater risk for sexually transmitted infections (STIs), including HIV [14-16].

Male violence against women, an extreme manifestation of gender inequality, is the direct result of gender norms that accept violence as a way to control an intimate partner. Men's use of violence against women and girls is a human rights violation. When it exists in a relationship, it may be impossible for the woman or girl to initiate and maintain HIV-protective

behaviors. A multi-country study found that between one-fifth and one-half of women of reproductive age have experienced physical violence by a male partner [17]. Data from a South African study found intimate partner violence to be significantly associated with HIV infection among women attending antenatal care centers [18].

Despite growing awareness that changing inequitable gender norms is key to successful HIV prevention efforts [13, 19, 20], few interventions attempted to address these norms, and even fewer measured the effects of such interventions. Additionally, most reproductive health interventions had focused primarily on women, with little attention paid to men [21]. To fill this gap, the Horizons Program and partners developed, implemented, and evaluated interventions to reduce HIV risk behaviors that engaged men in decision-making and that promoted gender-equitable attitudes and behaviors (Appendix). 


\section{Diagnosing the Problem}

To effectively address gender norms that contribute to HIV and STI risk, Horizons' first task was to better understand men's and women's beliefs and experiences about masculinity, gender, and sexuality; identify inequitable gender norms prevalent in study communities; and determine whether male support for them correlates with negative HIV-related outcomes such as unprotected sex and STI symptoms.

In Brazil, Horizons and partners built on qualitative research of young men in a low-income community [22]. This study revealed a prevailing version of masculinity characterized by limited male involvement in reproductive health and child care, a sense of male entitlement to sex from women, and tolerance of violence against women. A minority of more "gender equitable" men were also described. These men sought relationships built on intimacy and equality, assumed some responsibility for reproductive health issues, and did not behave violently in intimate relationships. These findings, shaped the development of survey questions to assess the extent to which young men were "gender equitable" [15, 23]. These questions clustered around four domains: sexual relationships, domestic chores and daily life, reproductive health and disease prevention, and violence. Later, the survey was administered to a similar population of young men as part of an intervention study. Baseline results show that more than half of the respondents agreed with the statement, "Men need sex more than women do." More than a third believed that "changing diapers, giving kids a bath, and feeding kids are the mother's responsibility." And about a fourth "would be outraged if my wife asked me to use a condom". These men also reported substantial STI and HIV risks (Table 1) [24].

Another Horizons study explored issues around masculinity in India with similar results [25]. Young male respondents identified qualities of a "real man" as: dominance expressed as physical and verbal aggression directed at other men and at women; virility without feminine mannerisms; expression of sexual power by sexually provocative and coercive behaviors toward women such as making derogatory comments, whistling, jostling, and unwanted touching. An ideal woman was defined as one who does not respond to men's sexual advances and is therefore marriageable. The informants said that women who raise the issue of condom use or carry their own condoms deserve sexual harassment and sexual coercion. In addition, results from a survey similar to that used in the Brazil study revealed that 42 percent felt it

Table 1 Selected HIV/STI risk profile at baseline at three study sites in Brazil

$\begin{array}{ccc}\text { Bangu } & \text { Maré } & \text { Morro dos } \\ \mathrm{n}=258 & \mathrm{n}=250 & \text { Macacos } \\ & & \mathrm{n}=272\end{array}$

\begin{tabular}{lccc}
\hline Mean age at first sex & 13 & 13 & 13 \\
\hline & $\%$ & $\%$ & $\%$ \\
\hline 2 partners in past month & 41 & 46 & 39 \\
STI symptoms during last 3 months & 23 & 31 & 18 \\
Condom use at last sex with primary partner & 58 & 69 & 64 \\
Physical violence against current or most recent partner & 5.9 & 10 & 12 \\
Ever taken HIV test & 5.8 & 6.0 & 10 \\
\hline
\end{tabular}


was the man who decides what type of sex to have. More than a third believed that a man should have the final word about decisions in the home, a woman should tolerate violence to keep her family together, and it is a woman's responsibility to avoid getting pregnant.

In Ethiopia, Horizons researchers examined similar domains among urban and rural married men [26]. As in Brazil and India, Horizons and partners found that many supported inequitable norms related to gender roles. About half felt that a woman should not initiate sex, that a woman should obey her husband in all things, and that a woman doesn't deserve respect if she has had sex before marriage. Nearly a third felt that women who carry condoms are promiscuous. And about one-quarter of male survey respondents agreed with each of six items supporting violence against intimate partners. For example, 23 percent of men agreed with the statement "there are times when a woman deserves to be beaten," and 59 percent felt that a woman should tolerate violence to keep her family together.

In Tanzania, qualitative research revealed the interrelationship between violence against female partners and infidelity. Horizons and partners found high levels of infidelity among young couples and that infidelity or the perception of it is the most common trigger for violence, condoned by many men and some women. For men, violence is justified when women lie to their partners and must be "taught" right from wrong. According to one informant, "There's time they need a teaching." There was also widespread

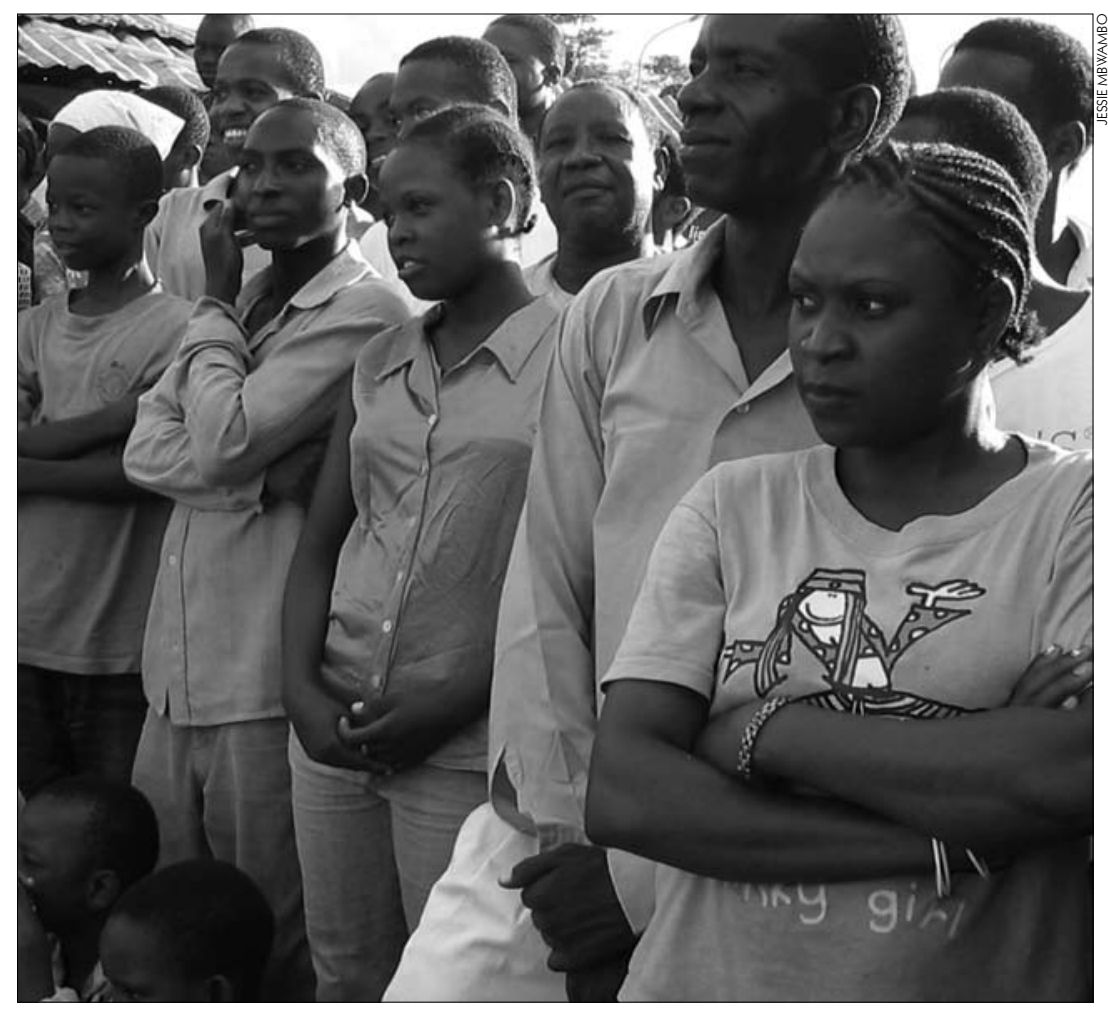

In Tanzania Horizons research found that many male and female youth distrust their sexual partners and accept partner violence as the norm.

acknowledgement that women expect men to provide economic support as part of a sexual relationship. Respondents said that women expect their male partners to provide them with money and gifts, but mistrust men because they often make false promises in order to have sex. On the other hand, men mistrust women's intentions, concerned that women's primary motivation for the relationship is financial support [27]. frequent trigger for violence in their relationships. "When a woman isn't faithful there's a need to use force," said a married man.
Because of the high levels of infidelity and the transactional nature of many sexual interactions, many male and female youth in the Tanzanian study distrusted their sexual partners and accepted partner violence as the norm. Findings from a quantitative sur- 
vey of young men in the same communities revealed that more than a third agreed there is nothing a woman can do if her partner wants to have other girlfriends. About half believed that a woman should tolerate beatings from her partner to keep the family together [28].

Acceptance of violence against women was also common among women surveyed at a Tanzanian center for voluntary counseling and testing for HIV (VCT) [29]. Female VCT clients who tested positive for HIV were significantly more likely to have experienced physical or sexual violence from their current sexual partners, compared to women who tested negative. In fact, HIV-positive women under age 30 were 10 times more likely to report violence than their HIV-negative counterparts [30].

Male involvement during pregnancy is a critical opportunity for HIV prevention. Pregnancy provides an opening to foster communication by capitalizing on both members' interest in

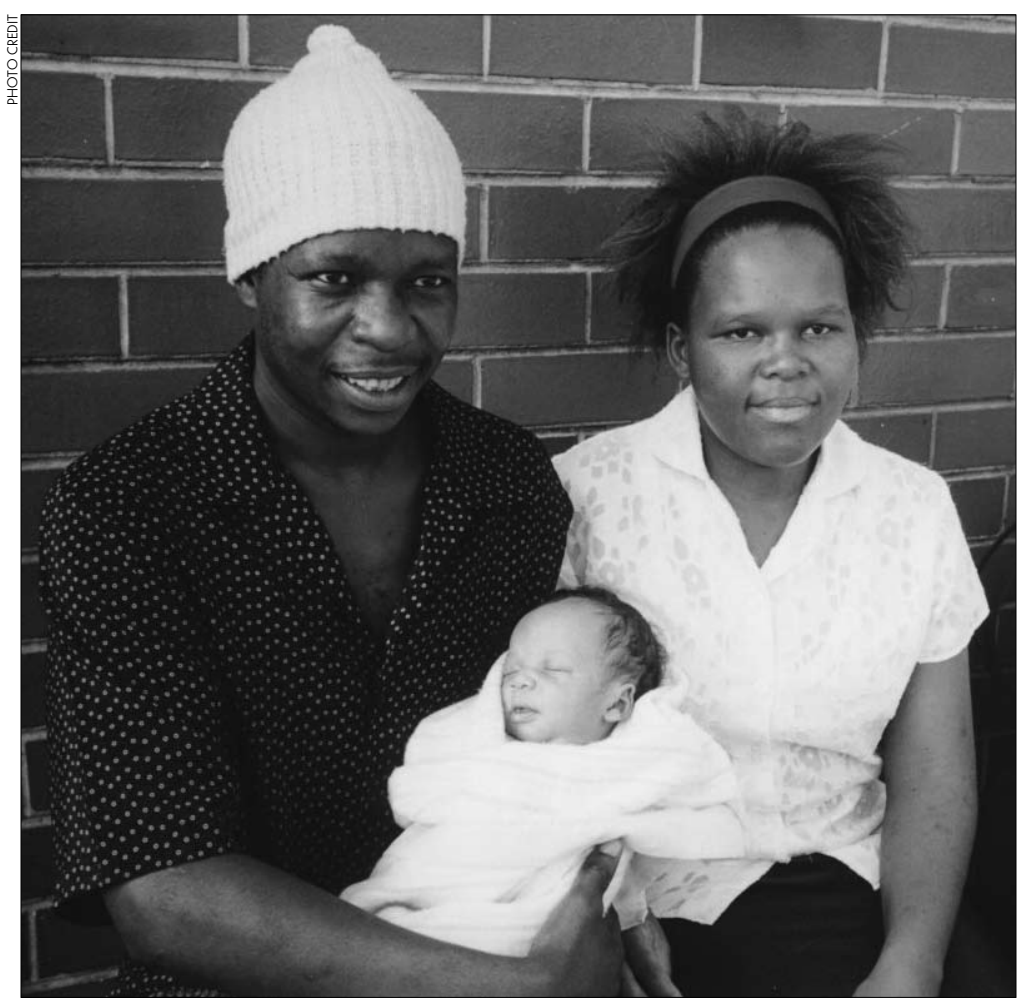

Horizons researchers found that gender norms that frame pregnancy as a woman's domain may prevent male involvement in antenatal care in Zimbabwe. the physical and social well-being of the mother and child. A Horizons study in Zimbabwe found that female respondents expected men to be more involved in pregnancy than the men themselves intended to be; while the men focused on financial support and passive involvement, the women also expected emotional support, accompaniment to antenatal appointments, and help with domestic chores. The researchers found that gender norms that frame pregnancy as a woman's domain and the pervasiveness of unwelcoming clinic environments for men who accompany their wives to care, are barriers to male involvement in antenatal care $[31,32]$.

In a Horizons evaluation study of UN-supported pilot programs in 11 countries, mainly in sub-Saharan Africa, on prevention of mother-to-child transmission of HIV (PMTCT), male involvement and support were recognized as critical to improving women's uptake of core PMTCT services, including:

- the decision to test;

- returning for test results;

- correctly taking antiretroviral drugs; and

- choosing and carrying out an infant feeding method.

The evaluation found limited efforts in these programs to engage and educate men to get their support for PMTCT services [33].

Several Horizons studies showed significant correlations between support for inequitable gender norms and risk for HIV and other STIs. For example, young men from rural sites in India who held inequitable gender beliefs were significantly more likely than more equitable men to have sex with more than one partner, be physically or sexually abusive against a partner, and report STI symptoms [5].

Likewise, in Brazil, endorsement of inequitable gender norms was significantly associated with reported STI symptoms, less contraceptive use, 
and both physical and sexual violence against a current or recent partner [24]. Horizons and partners also found evidence that support for equitable gender attitudes can be protective: In the Ethiopia study, men with gender-equitable attitudes were more likely to report healthy intimate partner behaviors, such as discussing and using condoms and other contraceptives [26].

\section{Using Innovative Intervention Strategies}

The above findings helped inform the intervention strategies that Horizons and partners developed and evaluated. Specifically, results from these studies demonstrate the importance of engaging men as partners in challenging inequitable gender norms in their communities, of facilitating critical reflections on gender inequality and its impacts on the lives of both women and men, and of helping men take on more proactive roles in HIV prevention and childcare. This section highlights selected findings and insights from intervention studies that Horizons and partners implemented over the course of the program.

\section{Engaging men in thinking critically about gender inequality}

In Brazil, researchers investigated the impacts of interactive group education sessions for young men and a community-wide "lifestyle" social marketing campaign that used genderequitable messages to promote safer sex and healthier relationships called Program $\mathrm{H}$ (for men, or homens in Portuguese) [24]. Activities in the group education sessions included role plays, brainstorming exercises, discussions, and individual reflection, led by adult male facilitators. Both the group sessions and the social marketing campaign aimed to promote critical thought on gender norms by encouraging young men to reflect on how they act as
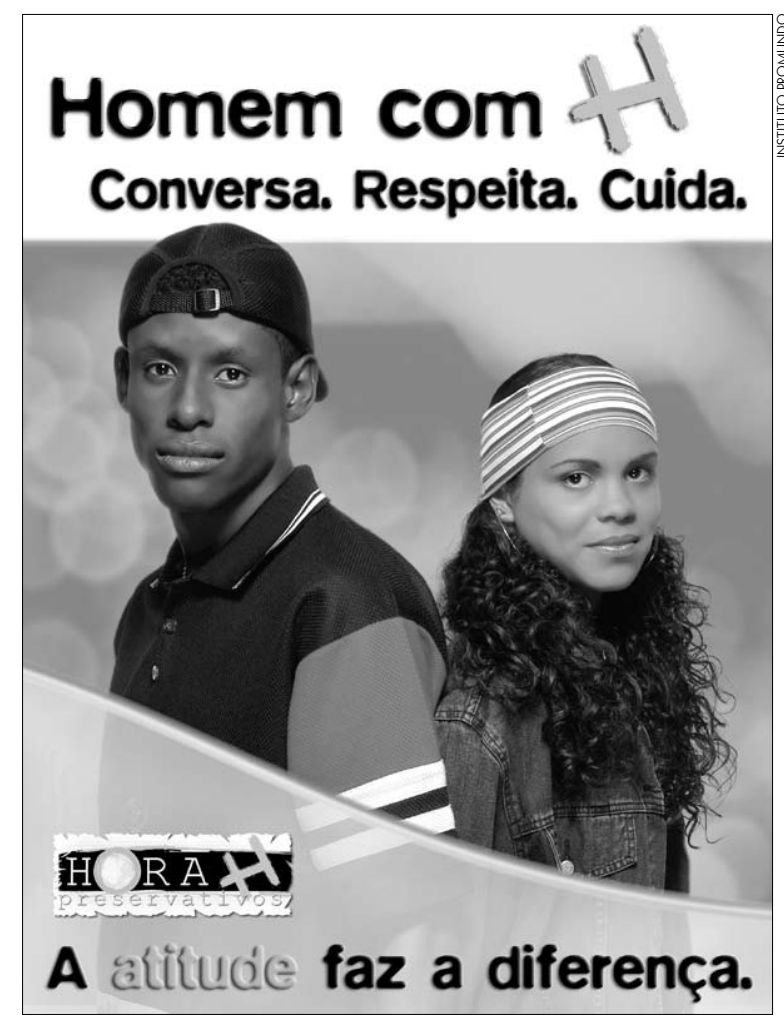

Horizons research showed that combining group education and social marketing can be a successful strategy for making young men's beliefs about gender more equitable. This poster was used in lifestyle social marketing campaign. "Talk.

Respect. Care. Attitude makes a difference."

men, while also enjoining them to respect their partners, avoid using violence against women, and practice safer sex [24]. The three-arm study encompassed a group education-only arm, a combination of group education sessions and a social marketing campaign arm, and a delayed intervention arm that served as the control.

Qualitative data from intervention participants demonstrated the effectiveness of helping young men actively reflect on the ways that gender inequality plays out in their own lives. For example, one young man described a new perspective on how his actions may affect his partners:

Before [the workshops] I had sex with a girl... and then left her. If I saw her later, it was like I didn't even know her. If she got 
pregnant or something, I had nothing to do with it. But now, I think before I act or do something. [24]

Quantitative data also showed the effectiveness of engaging men to reflect critically on their roles and relationships with lasting reductions (i.e., greater than six months) in support for inequitable gender norms in both intervention groups [24]. Moreover, for the two intervention sites, reported condom use with primary partners increased, STI symptoms were reduced, and decreases in agreement with inequitable gender norms over one year were significantly associated with decreased reports of STI symptoms.

In India, a modified version of the Brazil intervention resulted in significant reductions in support for inequitable gender norms among men in urban and rural communities. Depending on the study site, males in the intervention groups also reported significant positive changes in reported condom use at last sex, partner communication, sexual health problems, including STI symptoms, and partner violence. Intervention participants spoke of the value of critically reflecting on gender roles and relationships:

\section{After the session of gender and discussions with the peer leaders, I realized the impor- tance of my wife. Slowly, slowly I started discussing with her, started helping with her work and this has created more love and affection. I started respecting her and one day she requested me to keep away from my girlfriends... I have accepted it. [5]}

\section{Including interactive, small-group sessions and community-based activities}

Horizons studies demonstrated the effectiveness and feasibility of interactive, small-group education sessions to promote more equitable gender norms among young men. In both Brazil and India, weekly small-group sessions over the course of four to six months, used interactive exercises to cover such topics as gender and sexuality; STI/HIV risk and prevention; partner, family, and community violence; the reproductive system; alcohol and risk; and HIV-related stigma and discrimination $[24,5]$.

Facilitators of the group sessions in Brazil saw that it was important for the young men to participate in "male-only" groups, safe spaces to openly address various key topics. The young men appreciated the opportunity "to be here among men and to be able to talk" [24]. In India, the sessions prompted intense debate and discussions, and young men often drew examples from their own life experiences, an indicator of the relevance of the methodology and the themes for their personal lives [5].
Young men participating in a group session on masculinity, part of the Yari-dosti program in Mumbai, India. This Horizons study showed that group-based interventions for young men can successfully improve factors related to HIV risk. 
The quasi-experimental study designs in Brazil and India allowed Horizons researchers to compare the effectiveness of group education alone to group education plus community activities for reducing gender inequitable norms. In Brazil, the positive changes supporting equitable gender norms were equally great for young men exposed to the combination of group education activities and the community-based social marketing campaign, and for the group participating only in group education activities. However, it was only the combined intervention that led to significant changes in HIVrelated outcomes (e.g., increased condom use) [24]. In India, both arms of the intervention (group education sessions alone, and group sessions plus a community-based campaign that included street theatre) led to significant positive changes in gender norms and HIV-related outcomes [5]. No positive changes were found among the control groups in either Brazil or India.

These findings underscore the success of the group education sessions at addressing deepseated and complex gender-related norms, plus the impact of community-based activities in reinforcing HIV prevention messages with a gender perspective.

\section{Using the media to promote gender equity and HIV prevention}

In Nicaragua, Horizons and partners evaluated a communication for social change strategy targeting young people that encouraged responsible sex, open communication about sensitive topics, condom use, and empowerment of women. The project aimed to foster discussions about social and cultural issues that hinder HIV prevention among young people, such as gender inequity, partner violence, and stigma

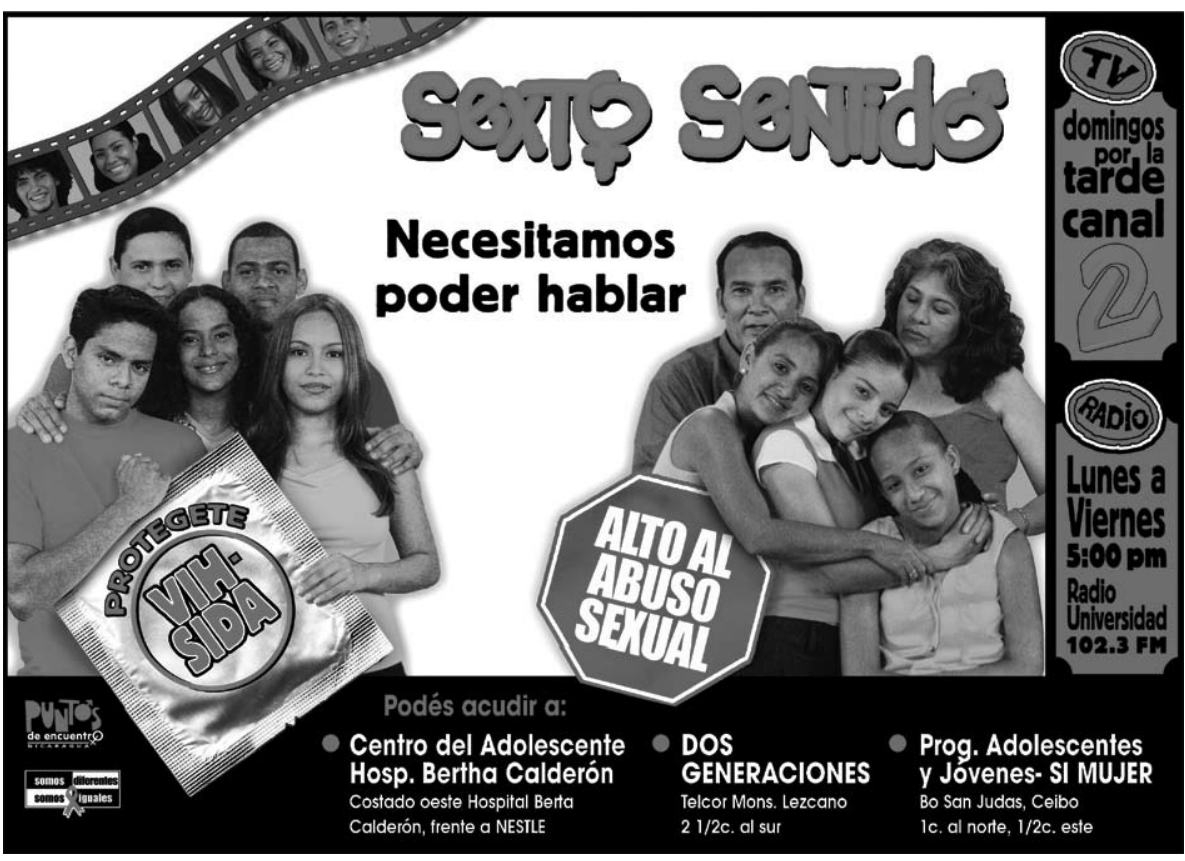

Horizons found that young people with the highest exposure to the Sexto Sentido intervention - which included a soap opera series, a radio show, and communitybased activities (such as youth camps)_became significantly more gender equitable. and discrimination. Seeking to address these issues, the intervention developed an accessible and entertaining television soap opera series called Sexto Sentido (Sixth Sense), which included characters who modeled genderequitable behaviors related to sexual health and relationships, partner violence, and women's status. The intervention also included a youthdirected radio show, and various communitybased activities (e.g., youth camps) [34].

After following a representative cohort of 3,099 youth aged 13 to 24 from three large cities over two years, the researchers found that overall support for gender-equitable norms increased over time. But individuals with the highest level of exposure to the intervention became significantly more "gender equitable," compared to those with lower levels of exposure. There was also an increase in knowledge about and use of HIV-related services and a significant increase in interpersonal communication about HIV prevention and sexual behavior [34]. These findings suggest that communication for social change programs can be an effi- 
cient strategy both for reaching large numbers of young people and for effecting measurable change in gender attitudes and norms on a population level.

\section{Reaching men directly when their partners are pregnant}

In a PMTCT program in Kenya, staff recognized the dissatisfaction and lack of interest of men who only received information through their partners. In response, staff introduced a specifc set of activities targeting men directly. These activities included inviting men to the clinic for HIV testing, providing community education on PMTCT in places where men congregate, and holding support groups for men [33]. Horizons' evaluation of these strategies documented that they led to significant increases in HIV-related discussions between pregnant women and their partners, HIV testing of male partners of PMTCT clients, and disclosure of HIV results by both women and men to a regular partner.
A Horizons study in Zimbabwe explored whether promoting male involvement in their partners' pregnancy and antenatal care would result in increasing HIV/STI protective behaviors [32]. The intervention included community outreach, male-oriented educational materials, a group talk to antenatal clinic clients, and couples counseling by nurse midwives. Of all the intervention components, outreach activities showed most promise, successfully promoting community discussions and personal reflection about male involvement and sexual health. Community health workers conducted the outreach activities, which included such interactive strategies as picture cards, role play, posters, and flash cards. Couples counseling was the weakest component, due to counselor attrition, limited participation by male partners, and the difficulty of counseling on sensitive topics. Despite these challenges, the nurse midwives felt there was a need for providing information and counseling to couples because often only one member was HIVpositive or infected with another STI.

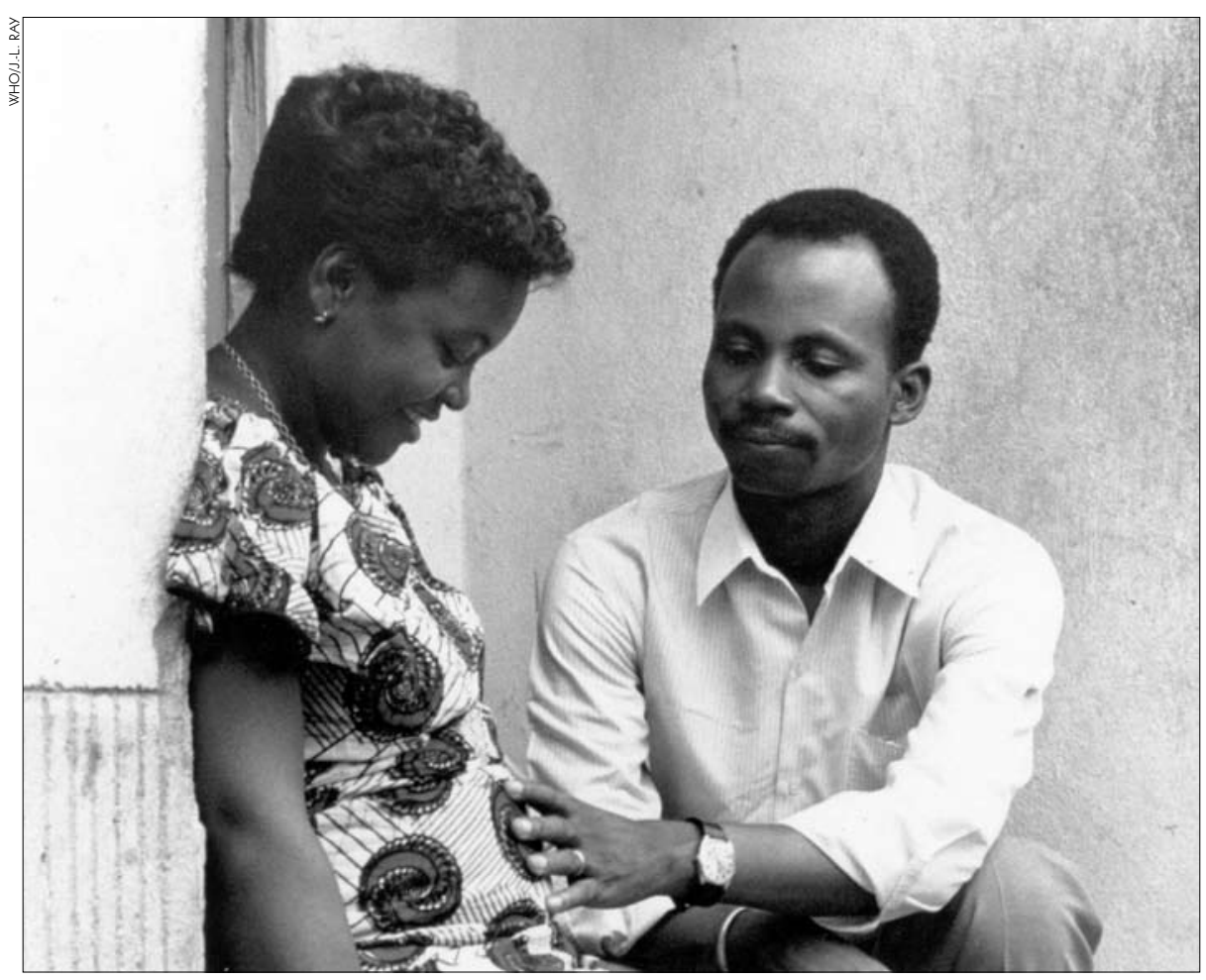

A Horizons intervention in Zimbabwe showed that outreach activities best promoted male involvement in their partners' antenatal care.
Recognizing that some inequitable attitudes are more difficult to change

Findings from Horizons studies indicate that certain key inequitable beliefs may coexist with generally equitable norms. For example, in the Brazil study, some young men reported respect for women and repudiated violence against women. They believed they should use condoms and discuss condom use with their partners. However, they also reported that men have a "right" to have outside sexual partners [24].

In the Nicaragua study, while some increases in gender equity were observed, many attitudes did not change. For example, there was less support at the end of the study for 
the statement, "women who carry condoms are easy," but the notion that men should have greater control over sexual relations stayed constant [34]. These examples highlight the inherent complexities of gender: some facets may be easier to change than others, and certain intervention strategies may be more appropriate for changing certain norms than others.

\section{Using Ground-breaking Research Methods: Measuring Gender Equity}

Before Horizons researchers began their work, few studies had attempted to quantitatively measure change in attitudes about gender norms, and few scales were available to evaluate an intervention's effects on gender norms and sexual risk behaviors In response to this important gap, Horizons researchers developed and validated the Gender-equitable Men (GEM) scale [35]. This scale includes items on women's and men's roles in domestic work and child care, sexuality and sexual relationships, reproductive health and disease prevention, violence, and homophobia and relations between men.

Box 1 displays examples of items from the original 24-item GEM scale developed in Brazil and Ethiopia, and from subsequent adaptations of the scale for India, where a few additional items were added in each context for cultural specificity $[5,26]$. In addition to Horizons studies, the GEM Scale is being used by other

\section{Box 1 The Gender-equitable Men Scale}

For each item in the scale, respondents indicate whether they agree, partially agree, or disagree. Topics include sexual and reproductive health and disease prevention, sexual relationships, violence, domestic life, and homosexuality.

Selected items from the original GEM scale (Brazil):

- It is the man who decides what type of sex to have.

- Women who carry condoms on them are "easy."

- A woman should tolerate violence in order to keep her family together.

- I would never have a gay friend.

- A couple should decide together if they want to have children.

Selected items from the India adaptation of the GEM scale:

- A man is happily married only if his wife brings a big dowry.

- A real man produces a male child.

Selected items from the Ethiopia adaptation of the GEM scale:

- A man using violence against his wife is a private matter that shouldn't be discussed outside the couple.

- A woman should not initiate sex.

researchers in such diverse settings as Mexico, Kenya, Uganda, and Thailand to study different populations of males and females.

The UNAIDS "2008 Report on the Global AIDS Epidemic" describes the GEM scale as "a practical and reliable way to measure key beliefs and norms that contribute to gender equality."

\section{"The GEM scale quantitatively measures changes in support for prevailing gender norms. These data, when combined with qualitative information, give researchers a good idea whether norms about gender roles are shifting within a community or sub-population, such as young men." equitable norms studies in Brazil and India}




\section{Future Research and Program Priorities}

Horizons operations research findings reveal that gender norms can play a powerful role in facilitating and condoning HIV risk behaviors. We also showed that strategies fostering equitable gender norms have an important place in HIV prevention programs. The studies conducted by Horizons and partners provide evidence for the effectiveness of group education interventions that involve high levels of participant interaction, critical reflection, and engagement. These studies also highlight the promise of mass media communication programs to raise awareness, spark dialogue about gender norms and sexual health, and increase genderequitable attitudes among men. Both smallgroup sessions (with their intensive impact on limited numbers of individuals) and mass media communications strategies (with their less intensive but broader reach) have a place in future efforts to increase equitable norms and improve sexual and reproductive health among men and women alike.

The past decade of Horizons' work on gender equity and HIV prevention has shown that addressing gender inequity - in particular, financial equity, safe spaces, and other economic and structural inequities - is a key means of reducing HIV risk, in the context of other important strategies. Horizons has focused on investigating programs that specifically target men. There is also a need to evaluate intervention strategies that involve both men and women. This work continues in India and Brazil, where parallel programs informed by the Horizons studies have been developed for girls and women that focus on promoting self-esteem and belief in one's abilities. Evaluations of different combinations of intervention activities for women, men, and both together are ongoing. Integrating both women and men as active partners in future interventions is likely to be a useful strategy for improving communication, collaboration, and mutual support between male and female participants. At the same time, the value of all-male and all-female initiatives should not be discounted, because they fill a particular role in providing "safe" spaces for men and women to express worries, share their personal stories, and seek advice. Further evaluations should also consider the use of biomarkers to provide additional evidence for determining intervention impact.

Future initiatives should also explore possibilities for programs that target gender norms in different settings and scale up success stories. Such strategies as the small-group educational workshops about gender norms could be inexpensively and efficiently integrated into many existing programs, such as school-based and community-based HIV education activities, voluntary counseling and testing initiatives, and
In India, Horizons expanded the work on sender equity and HIV prevention to women, focusing on self-esteem and critical thinking. 
support services for people living with HIV. In the process of integrating these kinds of initiatives into general HIV services, it is important for program implementers to include such effective interactive group activities as role playing, debating, and sharing personal stories.

Finally, it is important to build programs that support long-term, sustained change in gender norms by fostering broad-based, ongoing discussion on manhood, masculinity, and gender dynamics. Changing attitudes and behaviors is a complex and gradual process. The status quo supports male dominance, and both men and women are often unaware that these gender inequities even exist. Only a long-term strategy that includes a variety of approaches can successfully promote and support such changes. 


\section{APPENDIX}

\section{Summary of Horizons studies related to gender norms and HIV risk}

\begin{tabular}{|c|c|c|c|c|c|}
\hline Country & $\begin{array}{l}\text { Years of } \\
\text { study }\end{array}$ & Type of intervention & $\begin{array}{c}\text { Target } \\
\text { population }\end{array}$ & Sample size & $\begin{array}{c}\text { Type of study } \\
\text { (sampling technique) }\end{array}$ \\
\hline Brazil & $\begin{array}{l}2002- \\
2004\end{array}$ & $\begin{array}{l}\text { Small-group interactive education } \\
\text { sessions and mass media } \\
\text { communication for social change } \\
\text { program. }\end{array}$ & $\begin{array}{l}\text { Young men } \\
\text { (ages 14-25) }\end{array}$ & $\begin{array}{l}\text { Baseline: } 780 \\
\text { Mid-program: } \\
622 \\
\text { Endline: } 407\end{array}$ & $\begin{array}{l}\text { Longitudinal evaluation with } 3 \\
\text { rounds of data collection; } 2 \\
\text { intervention sites and } 1 \text { control } \\
\text { site (community-based sample). }\end{array}$ \\
\hline Ethiopia & 2007 & $\begin{array}{l}\text { Descriptive study testing } \\
\text { correlations between (in)equitable } \\
\text { gender norms and sexual health } \\
\text { behaviors. }\end{array}$ & $\begin{array}{l}\text { Married men } \\
\text { (ages 18-57) }\end{array}$ & $\begin{array}{l}\text { Single sample: } \\
522\end{array}$ & $\begin{array}{l}\text { One-time, face-to-face } \\
\text { surveys (multi-stage purposive } \\
\text { sampling). }\end{array}$ \\
\hline India & $\begin{array}{l}2004- \\
2005\end{array}$ & $\begin{array}{l}\text { Pilot of small group interactive } \\
\text { education sessions. }\end{array}$ & $\begin{array}{l}\text { Young men } \\
\text { (ages 18-29) }\end{array}$ & $\begin{array}{l}\text { Baseline: } 107 \\
\text { Endline: } 92\end{array}$ & $\begin{array}{l}\text { Longitudinal pre- and post- } \\
\text { intervention evaluation } \\
\text { (community-based sample). }\end{array}$ \\
\hline India & $\begin{array}{l}2006- \\
2007\end{array}$ & $\begin{array}{l}\text { Small-group interactive education } \\
\text { sessions and mass media } \\
\text { communication for social change } \\
\text { program. }\end{array}$ & $\begin{array}{l}\text { Young men } \\
\text { (ages 16-29) }\end{array}$ & $\begin{array}{l}\text { Baseline: } 1,915 \\
\text { Endline: } 1,138\end{array}$ & $\begin{array}{l}\text { Longitudinal pre- and post- } \\
\text { intervention evaluation with } 3 \\
\text { intervention sites ( } 2 \text { urban, } 1 \\
\text { rural) and } 2 \text { comparison sites } \\
\text { ( } 1 \text { urban, } 1 \text { rural) (systematic } \\
\text { sampling). }\end{array}$ \\
\hline Nicaragua & $\begin{array}{l}2002- \\
2005\end{array}$ & $\begin{array}{l}\text { Mass media communication for } \\
\text { social change program. }\end{array}$ & $\begin{array}{l}\text { Youth } \\
\text { (ages 13-24) }\end{array}$ & 3,099 & $\begin{array}{l}\text { Longitudinal panel study with } \\
\text { three data collection intervals, } \\
\text { each spaced } 1 \text { year apart } \\
\text { (cluster area random sampling). }\end{array}$ \\
\hline Tanzania & 1999 & $\begin{array}{l}\text { Descriptive study of women's } \\
\text { HIV disclosure decisions and } \\
\text { experiences of violence from male } \\
\text { intimate partners before and after } \\
\text { voluntary counseling and testing } \\
\text { for HIV. }\end{array}$ & $\begin{array}{l}\text { Male and } \\
\text { female voluntary } \\
\text { counseling and } \\
\text { testing clients }\end{array}$ & $\begin{array}{l}\text { Baseline: } 340 \\
\text { Endline: } 245\end{array}$ & $\begin{array}{l}\text { Qualitative interviews and } \\
\text { surveys before and } 3 \text { months } \\
\text { after VCT participation } \\
\text { (systematic sampling). }\end{array}$ \\
\hline Tanzania & $\begin{array}{l}2003- \\
2007\end{array}$ & $\begin{array}{l}\text { Community-based HIV and } \\
\text { violence prevention program. }\end{array}$ & $\begin{array}{l}\text { Young men } \\
\text { (ages 16-24) }\end{array}$ & $\begin{array}{l}\text { Baseline: } 951 \\
\text { Endline: } 581\end{array}$ & $\begin{array}{l}\text { Longitudinal pre- and post- } \\
\text { intervention evaluation with } \\
\text { matched comparison group } \\
\text { (systematic sampling). }\end{array}$ \\
\hline Zimbabwe & $\begin{array}{l}2002- \\
2004\end{array}$ & $\begin{array}{l}\text { Community outreach, educational } \\
\text { materials, and counseling sessions } \\
\text { promoting male involvement in } \\
\text { antenatal clinic (ANC) services. }\end{array}$ & $\begin{array}{l}\text { Pregnant women } \\
\text { and their male } \\
\text { partners }\end{array}$ & $\begin{array}{l}\text { Baseline: } 302 \\
\text { women, } 262 \text { male } \\
\text { partners } \\
\text { Endline: } 149 \\
\text { women, } 144 \text { male } \\
\text { partners }\end{array}$ & $\begin{array}{l}\text { Longitudinal pre- and post- } \\
\text { intervention study with ANC } \\
\text { clients (systematic sampling) } \\
\text { and their male partners. }\end{array}$ \\
\hline
\end{tabular}




\section{References}

1. "Report of the international conference on population and development" (International Conference on Population and Development, Cairo, Egypt, September, 1994).

2. "Platform for action" (Fourth World Conference on Women, Beijing, China, September, 1995).

3. M. E. Green et al., "Involving men in reproductive health: Contributions to development" (occasional paper prepared for United Nations Millennium Project, 2006).

4. J. Bruce, C. Lloyd, A. Leonard, Families in Focus: New Perspectives on Mothers, Fathers, and Children (New York: Population Council, 1995).

5. R. K. Verma et al., "Promoting gender equity as a strategy to reduce HIV risk and gender-based violence among young men in India," Horizons Final Report (Washington, DC: Population Council, 2008).

6. G. Barker, "What about boys? A review and analysis of international literature on the health and development needs of adolescent boys" (Geneva: WHO, 2000).

7. K. Rivers, P. Aggleton, "Men and the HIV epidemic, gender and the HIV epidemic" (New York: UNDCP HIV and Development Program, 1999).

8. C. A. Campbell, "Male gender roles and sexuality: implications for women's AIDS risk and prevention," Social Science Medicine 41 (2): 197-210 (1995).

9. G. M. Wingood, R. J. DiClemente, "Application of the theory of gender and power to examine HIV-related exposures, risk factors, and effective interventions for women," Health Education and Behavior 27 (5): 539-565 (2000).

10. W. Marsiglio, "Adolescent male sexuality and heterosexual masculinity: a conceptual model and review," Journal of Adolescent Research 3 (3-4): 285-303 (1988).

11. L. Morris, "Determining male fertility through surveys: Young adult reproductive health surveys in Latin America" (paper presented at the International Population Conference/Congres International de la Population, Montreal, Canada, August 24-September 1, 1993).
12. Childhope, "Gender, sexuality and attitudes related to AIDS among low income youth and street youth in Rio de Janeiro, Brazil” (New York: Childhope, 1997).

13. E. Weiss, D. Whelan, G. R. Gupta, "Gender, sexuality and HIV: making a difference in the lives of young women in developing countries," Sexual and Relationship Therapy 15 (3): 233-245 (2000).

14. H. Amaro, "Love, sex, and power. Considering women's realities in HIV prevention," The American Psychologist 50 (6): 437-447 (1995).

15. J. Pulerwitz et al., "Relationship power, condom use and HIV risk among women in the USA," AIDS Care 14 (6): 789-800 (2002).

16. P. Mane, G. R. Gupta, E. Weiss, "Effective communication between partners: AIDS and risk reduction for women," AIDS 8 (Suppl 1): S325-331 (1994).

17. L. Heise, M. Ellsberg, M. Gottemoeller, "Ending violence against women," Population Reports, Series L, No. 11. (Baltimore, MD: Johns Hopkins University School of Public Health, Population Information Program, 1999).

18. K. L. Dunkle et al., "Gender-based violence, relationship power, and risk of HIV infection in women attending antenatal clinics in South Africa," Lancet 363 (9419): 1415-1421 (2004).

19. T. M. Exner et al., "Beyond the male condom: the evolution of gender-specific HIV interventions for women," Annual Review of Sex Research in Health 14: 114-136 (2003).

20. S. L. Dworkin, A. A. Ehrhardt, "Going beyond "ABC" to include "GEM": critical reflections on progress in the HIV/AIDS epidemic," American Journal of Public Health 97 (1): 13-8 (2007).

21. J. M. Pile et al., "Involving men as partners in reproductive health: lessons learned from Turkey," AVSC Working Paper 12 (1999).

22. G. Barker, "Gender equitable boys in a gender inequitable world: reflections from qualitative research and programme development in Rio de Janeiro," Sexual and Relationship Therapy 15 (3): 263-282 (2000). 
23. J. Pulerwitz, S. L. Gortmaker, W. De Jong, "Measuring sexual relationship power in HIV/STD research," Sex Roles: A Journal of Research 42 (7/8): 637-660 (2000).

24. J. Pulerwitz et al., "Promoting more genderequitable norms and behaviors among young men as an HIV/AIDS prevention strategy," Horizons Final Report (Washington, DC: Population Council, 2006).

25. R. K. Verma et al., "Challenging and changing gender attitudes among young men in Mumbai, India," Reproductive Health Matters 14 (28): 135-143 (2006).

26. S. Middlestadt et al.,

"Gender norms as a key factor that influences SRH behaviors among Ethiopian men, and implications for behavior change programs" (unpublished manuscript).

27. H. Lary et al., "Exploring the association between $\mathrm{HIV}$ and violence: young people's experiences with infidelity, violence and forced sex in Dar es Salaam, Tanzania," International Family Planning Perspectives 30 (4): 200-206 (2004).

28. S. Maman and J. Mbwambo, "Evaluation of a community-based HIV and violence prevention intervention targeting young men in Dar es Salaam, Tanzania," Horizons Final Report (Washington DC: Population Council; unpublished).

29. S. Maman, "HIV and partner violence: Implicataions for HIV voluntary counseling and testing programs in Dar es Salaam, Tanzania," Horizons Final Report (Washington, DC: Population Council, 2001).

30. S. Maman et al., "HIV-positive women report more lifetime partner violence: findings from a voluntary counseling and testing clinic in Dar es Salaam, Tanzania," American Journal of Public Health 92 (8): 1331-1337 (2002).

31. R. Marindo, "Sexual behaviour during pregnancy in urban Harare" (Harare: Centre for Population Studies, unpublished manuscript).

32. R. Marindo, E. Weiss, J. Pulerwitz, "Promoting male involvement and HIV prevention during pregnancy in Zimbabwe," Horizons Research Summary (Washington, DC: Population Council, 2004).

33. N. Rutenberg et al., "Evaluation of United Nations-supported pilot projects for the prevention of mother-to-child transmission of HIV: Overview of findings" (New York: UNICEF, 2003).

34. I. Solórzano et al., "Catalyzing personal and social change around gender, sexuality, and HIV: Impact evaluation of Puntos de Encuentro's communication strategy in Nicaragua," Horizons Final Report (Washington, DC: Population Council, 2008).
35. J. Pulerwitz, G. Barker, "Measuring attitudes toward gender norms among young men in Brazil: Development and psychometric evaluation of the GEM Scale," Men \& Masculinities 10 (3): 322-338 (2008). 


\section{ACKNOWLEDGEMENTS}

The Horizons research studies reviewed in this synthesis paper were conducted in collaboration with the following implementing and research partners, whose cooperation and input were vital: Instituto PROMUNDO, CORO for Literacy, MAMTA, DAUD, Miz-Hasab Research Center, Center for Communication Programs, Academy for Educational Development, Muhimbili University, University of Dar es Salaam Drama Department, Johns Hopkins University Bloomberg School of Public Health, Puntos de Encuentro, CIDS/UNAN Leon, and the University of Zimbabwe. In addition the authors gratefully acknowledge the following people who helped in preparing this paper: Scott Kellerman, Naomi Rutenberg, and LeeAnn Jones of the Population Council. Thanks to Gina Duclayan, Hena Khan, and Deborah Weiss for editing and Sherry Hutchinson for layout. 
Authors: Julie Pulerwitz, Horizons/PATH; Annie Michaelis, Horizons/Population Council; and Ellen Weiss, Horizons/International Center for Research on Women
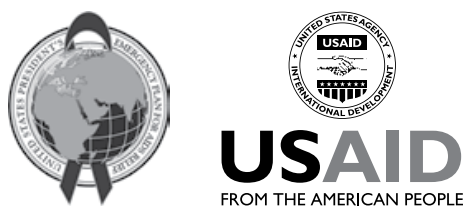

Program and do not necessarily reflect the views of USAID or the United States Government.

This study and final report were made possible by the President's Emergency Plan for AIDS Relief and the generous support of the American people through the United States Agency for International Development (USAID) under the terms of Cooperative Agreement No. HRNA-00-97-00012-00. The contents are the responsibility of the Horizons

Published in April 2010.

(1) Population Council

The Population Council is an international, non-profit, nongovernmental institution that seeks to improve the well-being and reproductive health of current and future generations around the world and to help achieve a humane, equitable, and sustainable balance between people and resources. The Council conducts biomedical, social science, and public health research and helps build research capacities in developing countries. Established in 1952, the Council is governed by an international board of trustees. Its New York headquarters supports a global network of regional and country offices.

Copyright (C) 2010. The Population Council Inc.

Suggested citation: Pulerwitz, Julie, Annie Michaelis, and Ellen Weiss. 2010. "Looking back, moving forward: Promoting gender equity to fight HIV, Horizons studies 1999 to 2007," Horizons Synthesis Background Papers. Washington, DC: Population Council.

This document may be reproduced in whole or in part without permission of the Population Council provided full source citation is given and the reproduction is not for commercial purposes. 


USAID

Population Council

HIV and AIDS Program

4301 Connecticut Ave NW, Suite 280

Washington, DC 20008

Tel: 202-237-9400

Fax: 202-237-8410

pubinfo@popcouncil.org 